\title{
Cigarette smoking and risk of rheumatoid arthritis: a dose-response meta-analysis
}

\author{
Daniela Di Giuseppe, Andrea Discacciati, Nicola Orsini and Alicja Wolk*
}

\begin{abstract}
Introduction: Although previous studies found that cigarette smoking is associated with risk of rheumatoid arthritis (RA), the dose-response relationship remains unclear. This meta-analysis quantitatively summarizes accumulated evidence regarding the association of lifelong exposure to cigarette smoking assessed as pack-years with the risk of RA.

Methods: Relevant studies were identified by a search of MEDLINE and EMBASE from 1966 to October 2013, with no restrictions. Reference lists from retrieved articles were also reviewed. Studies that reported relative risks (RR) or odds ratio (OR) estimates with 95\% confidence intervals (Cls) for the association between pack-years of cigarette smoking and rheumatoid arthritis were included in a dose-response random-effects meta-regression analysis.

Results: We included 3 prospective cohorts and 7 case-control studies in the meta-analysis. They included a total of 4,552 RA cases. There was no indication of heterogeneity $\left(P_{\text {heterogeneity }}=0.32\right)$ and publication bias did not affect the results. Compared to never smokers, the risk of developing RA increased by $26 \%$ ( $R R=1.26,95 \% \mathrm{Cl} 1.14$ to 1.39) among those who smoked 1 to 10 pack-years and doubled among those with more than 20 pack-years (RR for 21 to 30 pack years $=1.94,95 \% \mathrm{Cl} 1.65$ to 2.27). The risk of RA was not increasing further for higher exposure levels (RR for $>40$ pack-years $=2.07,95 \% \mathrm{Cl} 1.15$ to 3.73 ). The risk of RA was statistically significantly higher among rheumatoid factor (RF)-positive RA cases ( $R R=2.47,95 \% \mathrm{Cl} 2.02$ to 3.02) compared to RF-negative ( $R R=1.58,95 \% \mathrm{Cl} 1.15$ to 2.18) when comparing the highest versus lowest category of pack-years for the individual studies.
\end{abstract}

Conclusions: Lifelong cigarette smoking was positively associated with the risk of RA even among smokers with a low lifelong exposure. The risk of RA did not further increase with an exposure higher than 20 pack-years.

\section{Introduction}

Cigarette smoking is considered an established risk factor for the development of rheumatoid arthritis (RA), an autoimmune inflammatory disease. This was confirmed by a published meta-analysis on smoking and risk of RA that showed a $40 \%$ higher risk among ever smokers compared to never smokers [1]. However, little is known regarding the dose-response relationship between quantity of cigarette smoking and increase in the risk of RA. Previous epidemiological studies showed an increasing RA risk associated with increasing cigarette smoking [2-4], while a recently published study reported that even light smoking was associated with an increased risk of RA [5]. Light smoking as well as heavy smoking could increase the risk

\footnotetext{
* Correspondence: Alicja.Wolk@ki.se

Division of Nutritional Epidemiology, Institute of Environmental Medicine, Karolinska Institutet, Nobels vag 13, Stockholm 171 77, Sweden
}

of RA due to the triggering of the immune system against citrullinated proteins antigens [6].

The aim of the present study was to quantitatively summarize the accumulated evidence on the relation between lifelong exposure to cigarette smoking and risk of developing rheumatoid arthritis by performing a dose-response meta-analysis. As a measure of lifelong exposure we used pack-years of smoking.

\section{Methods}

We searched MEDLINE and EMBASE databases for relevant studies published from 1966 through October 2013 using the search terms "rheumatoid arthritis" or "RA" combined with "smoke", "smoking", "cigarette smoking" or "pack-years", with no restrictions. Studies were excluded if they did not meet the selection criteria: use of an observational design (cohort or case-control design), examination of smoking as the main exposure and RA as the main

\section{Biomed Central}


outcome, reporting relative risks or odds ratios of RA for categories of pack-years (obtained by multiplying the number of cigarettes smoked per day by the number of years the person has smoked, divided by 20). In case of multiple publications from the same study, we selected the publication with estimates on the entire study cohort $[2,4]$, instead of the publications focusing only on interactions [7] or anticitrullinated protein antibody (ACPA) positive RA cases [8].

From each study we extracted information regarding publication data (first author's last name, year of publication and country of the studied population), number of RA cases, cohort size or number of controls, follow-up period for cohorts and study period for case-control studies, exposure specific relative risk or odds ratio estimates with their corresponding 95\% confidence intervals (CIs), and variables controlled for in the multivariable model (Table 1). From each study, we extracted the relative risk or odds ratio estimates from the maximally adjusted model to reduce the risk of possible unmeasured confounding. Data were extracted independently by two researchers (DDG and NO).

The study quality was assessed using the NewcastleOttawa Quality Assessment Scale (NOQAS) for cohort and case-control studies, with which each study was judged based on the selection of the study groups, the comparability of the groups, and the ascertainment of exposure and outcome [9]. The score ranged between 0 (as poor) and 9 (as excellent). The present work follows the recommendations of the PRISMA Statement [10].

\section{Statistical analysis}

We conducted a two-stage dose-response random-effects meta-regression analysis [11,12], and we estimated the dose-response relationship curve by taking into account the covariance among risk estimates for different exposure categories [12]. The possible non-linear relationship between pack-years of smoking and risk of RA was modeled using restricted cubic splines (with three knots). This method requires stating the distribution of cases and noncases or person-time and the relative risk (RR) or the odds ratio (OR) with its confidence intervals for at least three quantitative exposure categories. For this reason, a study that reported only two exposure categories was excluded from this meta-analysis [13]. For another study that did not provide the distribution of cases and non-cases for each exposure level [14], we used the method proposed by Hamling et al. [15] to calculate the pseudo-counts to be able to estimate the covariance of the published ORs. For a study that reported only results stratified by menopausal status [16], we combined the two stratum-specific ORs using inverse variance weighted averages [17]. The midpoint of each exposure category was assigned to each corresponding risk estimate. We assigned the midpoint of the upper open-ended category assuming that they had the same amplitude as the preceding categories, except for one study [5], which reported the median value of the highest category. We assigned a null value to the lowest category, composed in all the studies by never smokers. By testing if the second parameter of the restricted cubic spline model was equal to 0 , we observed a limited evidence of a non-linear relationship between pack-years of smoking and RA $(P=0.078)$. However, the restricted cubic spline model resulted in the best fitting model in terms of the Akaike Information Criterion (AIC) when comparing it against a linear model $\left(\mathrm{AIC}_{\text {splines }}=-70.0 ; \mathrm{AIC}_{\text {linear }}=-57.4\right)$.

We additionally performed a random-effects metaanalysis comparing the highest versus the lowest category of pack-years within each specific study. For this analysis the approach developed by DerSimonian and Laird was used [17]. We conducted a sensitivity analysis in which one study at a time was removed in order to evaluate the influence of each study on the overall estimate. We also performed analyses stratified by study design (cohort, case-control), gender and rheumatoid factor (RF) type (positive, negative).

In all meta-regression models, statistical heterogeneity between studies was evaluated with the Cochran's Q-test and the $\mathrm{I}^{2}$ statistic [18], which assess the proportion of total variation due to between-study variation. Publication bias was investigated by Egger's regression asymmetry test [19]. All reported $P$-values are two-sided. All statistical analyses were carried out with Stata, version 12.1 (StataCorp, College Station, TX).

\section{Results}

Of the 29 studies that reported an estimate of the association between cigarette smoking and rheumatoid arthritis, only 3 cohort studies $[4,5,20]$ and 7 case-control studies $[2,14,16,21-24]$ evaluated the dose-response relationship between pack-years and RA, and were included in this meta-analysis (Figure 1). Of the 10 studies that met the predefined inclusion criteria, 4 were from North America $[4,14,16,20], 5$ from Europe [2,5,21,22,24], and 1 from Malaysia [23], and they included a total of 181100 subjects and 4,552 RA cases (Table 1). The median of the highest category of number of pack-years analyzed in each study ranged between 15 and more than 55 pack-years, while the reference group for all studies was never smokers. Four studies provided risk estimates for women only $[4,5,16,20]$ and two studies provided risk estimates for men and women separately $[21,22]$. Using the NOQAS quality assessment, all 10 studies were assessed to have moderate quality (Table 1). All studies included in this meta-analysis showed a significant dose-response increased risk, except one [21], which reported a non-significant positive association between RA and cigarette smoking among women.

In a dose-response analysis, we modeled the relationship between pack-years of cigarette smoking and RA risk using a restricted cubic splines model. The non-linear 
Table 1 Characteristics of studies on rheumatoid arthritis and pack-years

\begin{tabular}{|c|c|c|c|c|c|c|c|}
\hline Authors, year & $\begin{array}{l}\text { Study population, country, } \\
\text { follow-up period/study period }\end{array}$ & $\begin{array}{l}\text { Cases/cohort } \\
\text { size or controls }\end{array}$ & $\begin{array}{l}\text { Range of exposure } \\
\text { pack-years }\end{array}$ & $\begin{array}{l}\text { Highest } \\
\text { category }\end{array}$ & $\begin{array}{l}\text { RR/OR* Highest vs. lowest } \\
\text { category }(95 \% \mathrm{Cl})\end{array}$ & Controlled variables & NOQAS* \\
\hline \multicolumn{8}{|l|}{ Cohort } \\
\hline Criswell et al., 2002 [20] & $\begin{array}{l}\text { lowa Women's Health Study, } \\
\text { USA, } 1986 \text { to } 1997\end{array}$ & Women 158/31,336 & 0 to $50^{\mathrm{a}}$ & $\geq 40$ & Total 1.7 (1.0 to 3.0$)$ & $\begin{array}{l}\text { Age, body mass index, alcohol use, } \\
\text { coffee consumption, marital status, } \\
\text { occupation, age at menopause, use } \\
\text { of oral contraceptives and hormone } \\
\text { replacement therapy. }\end{array}$ & 8 \\
\hline Costenbader et al., 2006 [4] & $\begin{array}{l}\text { Nurses' Health Study, USA, } \\
1976 \text { to } 2002\end{array}$ & Women $680 / 103,818$ & 0 to $45^{\mathrm{a}}$ & $>40$ & $\begin{array}{l}\text { Total } 1.86 \text { (1.46 to } 2.38) \mathrm{RF}^{*}{ }^{*} 2.22 \\
\text { (1.63 to } 3.02) \mathrm{RF}^{*} 1.43 \text { (0.96 to } 2.12 \text { ) }\end{array}$ & $\begin{array}{l}\text { Age, body mass index, alcohol intake, } \\
\text { father's occupation, age at menarche, } \\
\text { menstrual regularity, duration of } \\
\text { breastfeeding, postmenopausal } \\
\text { hormone use. }\end{array}$ & 8 \\
\hline Di Giuseppe et al., 2013 [5] & $\begin{array}{l}\text { Swedish mammography } \\
\text { cohort, } 2003 \text { to } 2010\end{array}$ & Women 219/34,101 & 0 to $28^{\mathrm{b}}$ & $>22$ & Total 1.82 (1.19 to 2.79$)$ & $\begin{array}{l}\text { Age, menopause status, parity, alcohol } \\
\text { use, educational level, and body mass } \\
\text { index. }\end{array}$ & 8 \\
\hline \multicolumn{8}{|l|}{ Case-control } \\
\hline Voigt et al., 1994 [16] & $\begin{array}{l}\text { Population-based controls, } \\
\text { USA, } 1986 \text { to } 1991\end{array}$ & Women 349/1,457 & $0-27^{a}$ & $>20$ & Total 1.49 (1.06 to 2.10$)$ & Age, body mass index. & 7 \\
\hline Hutchinson et al., 2001 [24] & Hospital-based controls, UK & $\begin{array}{l}\text { Men }+ \text { Women } \\
\text { 239/239 }\end{array}$ & 0 to $55^{\mathrm{a}}$ & $>50$ & Total 8.41 (2.45 to 28.84$)$ & $\begin{array}{l}\text { Matched for age, gender and social } \\
\text { class. }\end{array}$ & 7 \\
\hline Olsson et al., 2001 [21] & $\begin{array}{l}\text { Population-based controls, } \\
\text { Sweden, } 1980 \text { to } 1995\end{array}$ & $\begin{array}{l}\text { Men 91/203 } \\
\text { Women } 154 / 222\end{array}$ & 0 to $27^{\mathrm{a}}$ & $\geq 20$ & $\begin{array}{l}\text { Total men } 2.7(1.2 \text { to } 5.8) \text { Total } \\
\text { Women } 1.8(0.7 \text { to } 4.6) \text { RF + Men } \\
3.4 \text { ( } 1.5 \text { to } 8.4) \text { RF + Women } 2.5 \\
\text { (0.9 to } 6.7)\end{array}$ & Age, economic status. & 7 \\
\hline Stolt et al., 2003 [2] & $\begin{array}{l}\text { Population-based controls, } \\
\text { Sweden, } 1996 \text { to } 2000\end{array}$ & $\begin{array}{l}\text { Men + Women } \\
486 / 724\end{array}$ & 0 to $25^{\mathrm{a}}$ & $\geq 20$ & $\mathrm{RF}+2.7(1.8$ to $3 . .9)$ & Age, residential area and gender. & 7 \\
\hline Pedersen et al., 2006 [22] & $\begin{array}{l}\text { Population-based controls, } \\
\text { Denmark, } 1988 \text { to } 2003\end{array}$ & $\begin{array}{l}\text { Men 149/291 Women } \\
366 / 478\end{array}$ & 0 to $25^{\mathrm{a}}$ & $>20$ & $\begin{array}{l}\text { Total men } 2.00 \text { ( } 1.12 \text { to } 3.58) \text { Total } \\
\text { Women } 2.07 \text { ( } 1.35 \text { to } 3.16)\end{array}$ & Birth year, year of RA diagnosis, gender. & 7 \\
\hline Mikuls et al., 2010 [14] & $\begin{array}{l}\text { Population-based controls, } \\
\text { US (African Americans) }\end{array}$ & $\begin{array}{l}\text { Men }+ \text { Women } \\
605 / 255\end{array}$ & 0 to $15^{\mathrm{a}}$ & $\geq 10$ & $\begin{array}{l}\text { Total } 2.37 \text { (1.56 to } 3.60) R F+2.51 \\
\text { (1.63 to } 3.87) \text { RF- } 1.93 \text { (1.11 to } 3.35)\end{array}$ & Age, gender. & 7 \\
\hline Yahya et al., 2012 [23] & $\begin{array}{l}\text { Population-based controls, } \\
\text { Malaysia, } 2005 \text { to } 2009\end{array}$ & $\begin{array}{l}\text { Men + Women } \\
\text { 1056/1416 }\end{array}$ & 0 to $25^{\mathrm{a}}$ & $\geq 20$ & Total 2.3 (1.0 to 5.5$)$ & $\begin{array}{l}\text { Matched for age, gender and residential } \\
\text { area. Additionally adjusted for formal } \\
\text { education and ethnicity. }\end{array}$ & 6 \\
\hline
\end{tabular}

${ }^{\mathrm{a} M i d p o i n t}$ in the lowest-highest category ${ }^{\mathrm{b}}$ Median of the highest category.

${ }^{\S}$ The lowest category corresponded to never smokers in all study except the study of Navarro-Compàn et al., that used $<20$ pack/years as reference level.

${ }^{*} \mathrm{Cl}$, confidence interval; NOQAS, Newcastle-Ottawa Quality Assessment Scale (score from 0 as poor to 9 as excellent); OR, odds ratio; RF+, rheumatoid factor positive; RF-, rheumatoid factor negative; RR, relative risk. 


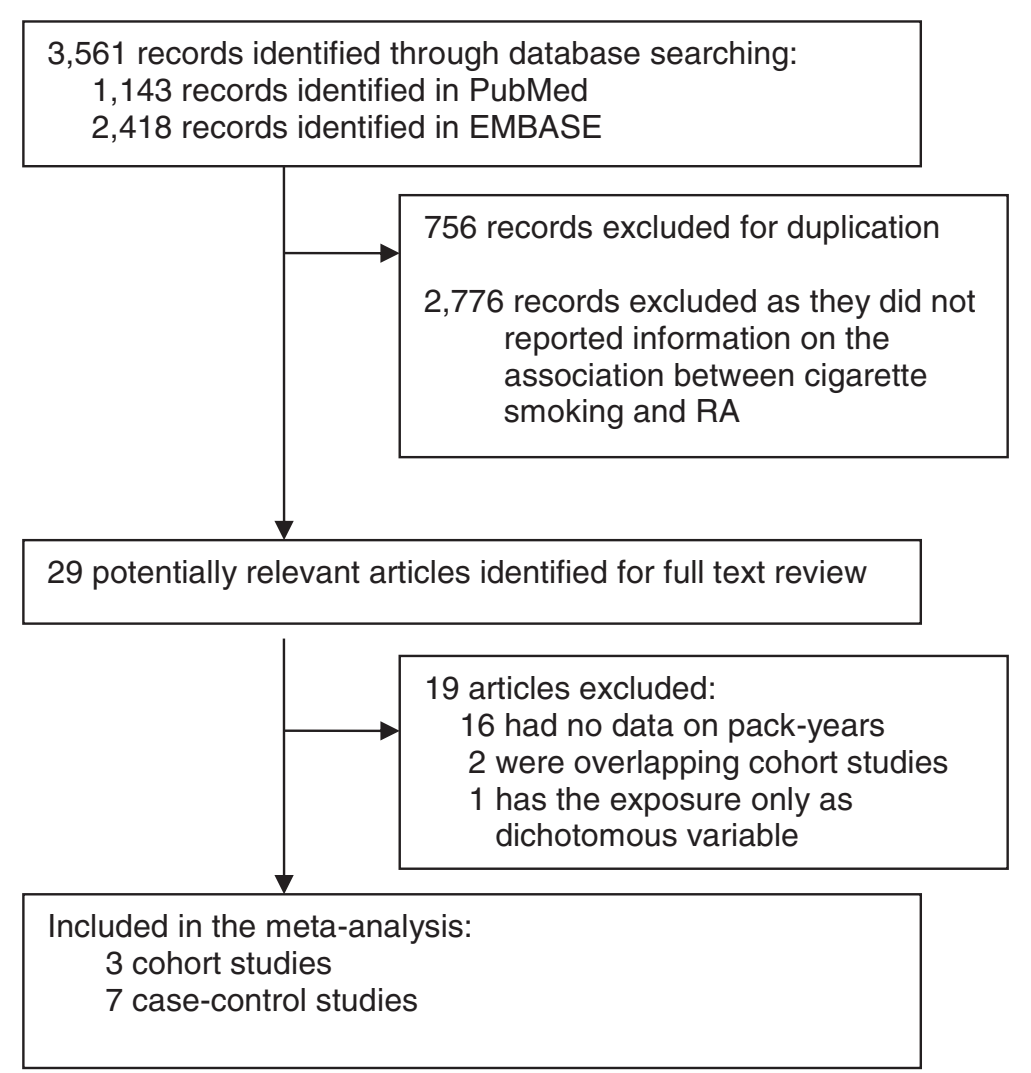

Figure 1 Flow chart of selection of studies for inclusion in the meta-analysis.

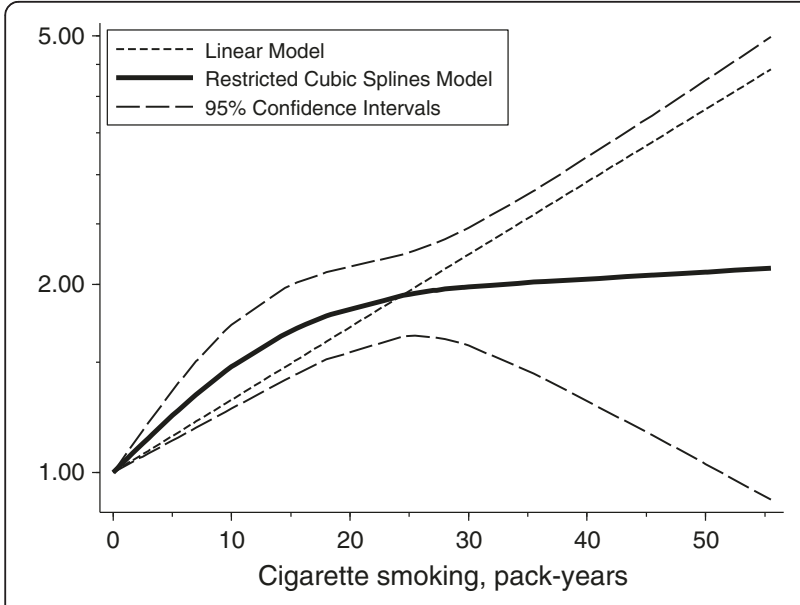

Figure 2 Non-linear dose-response relationship between pack-years of cigarettes smoking and relative risk of RA. Relative risk (solid line) and 95\% confidence interval (long dashed lines) from the restricted cubic splines model. The short dashed line represents the RR from the linear model. Estimates reported in the table are based on median value of each category. dose-response trend (Figure 2) showed a statistically significant increased risk of developing RA with increasing number of pack-years smoked up to 20 pack-years, and then the relative risk stabilized approximately at the value of 2 . The risk of RA was $26 \%$ higher ( $R R=1.26,95 \%$ CI 1.14 to 1.39 ) for those who smoked 1 to 10 pack-years of cigarette (median value 5.5) compared to never smokers, while the risk was two-fold for those smoking 21 to 30 pack-years ( $R R=1.94,95 \%$ CI 1.65 to 2.27 ) and was similar even for higher levels of cigarette smoking ( $R R$ for $>40$ pack-years $=2.07$, 95\% CI 1.15 to 3.73 ) (Table 2).

The comparison of the highest vs. the lowest categories of pack-years of smoking from the individual studies was

Table 2 Relative risks (RRs) and $95 \%$ confidence intervals ( $95 \% \mathrm{Cls}$ ) for categories of pack-years of smoking

\begin{tabular}{lc}
\hline Pack-years & RR $(\mathbf{9 5} \% \mathbf{C l})$ \\
\hline Never smokers & 1.00 \\
1 to 10 & $1.26(1.14$ to 1.39$)$ \\
11 to 20 & $1.70(1.44$ to 2.01$)$ \\
21 to 30 & $1.94(1.65$ to 2.27$)$ \\
31 to 40 & $2.02(1.44$ to 2.82$)$ \\
$>40$ & $2.07(1.15$ to 3.73$)$ \\
\hline
\end{tabular}


in line with the results from the dose-response analysis showing a two-fold increase of RA risk (overall $R R=2.02$, $95 \%$ CI 1.75 to 2.33 ). A sensitivity analysis excluding one study at a time showed that the overall RRs ranged between 1.92 and 2.10. Q test for heterogeneity of the results between specific studies was not statistically significant $\left(\mathrm{Q}=12.61, P_{\text {heterogeneity }}=0.32\right)$. There was no evidence of publication bias $(P$-value from the Egger's regression asymmetry test was 0.10$)$.

We conducted stratified analyses by study design, gender and rheumatoid factor type. The RR comparing the highest vs. the lowest category of pack-years of smoking was 1.83 (95\% CI 1.50 to $\left.2.23 ; \mathrm{Q}=0.09, P_{\text {heterogeneity }}=0.96\right)$ among cohort studies and $2.19(95 \%$ CI 1.76 to $2.72 ; \mathrm{Q}=11.22$, $\left.P_{\text {heterogeneity }}=0.19\right)$ among case-control studies (Figure 3). The RR estimate was 1.78 (95\% CI 1.52 to 2.08; Q $=1.69$, $\left.P_{\text {heterogeneity }}=0.89\right)$ among women and 2.22 (95\% CI 1.39 to 3.55; $\mathrm{Q}=0.36, P_{\text {heterogeneity }}=0.55$ ) among men. Four studies reported estimates for RF-positive RA [2,4,14,21] and only two for RF-negative RA $[4,14]$. Among RFpositive cases the RR comparing the highest vs. the lowest category of pack-years of smoking was 2.47 (95\% CI 2.02 to 3.02; $\left.P_{\text {heterogeneity }}=0.88\right)$, while it was $1.58(95 \%$ CI 1.15 to $\left.2.18, P_{\text {heterogeneity }}=0.39\right)$ among RF-negative cases. These estimates were statistically significantly different $(P$-value 0.022).

\section{Discussion}

The findings from this dose-response meta-analysis showed some evidence of a non-linear association between lifelong cigarette smoking and RA. The association was statistically significant even among those smoking less than 10 packyears. For more than 20 pack-years the risk of RA was two-fold compared to never smokers and it stabilized with no further increase for higher levels. The risk among RF-positive RA cases was statistically significantly higher than the risk among those RF-negative.

The dose-response meta-analysis was based on a limited number of studies. Only 10 studies satisfied the inclusion criteria, of which only 3 were prospective cohort studies. In the analyses we did not observe evidence of heterogeneity. Publication bias did not affect the findings of this meta-analysis. Results from this meta-analysis are in line with the results from the previous meta-analysis [1], showing an increased RA risk associated with cigarette smoking. However, this meta-analysis of the dose-response relationship between cigarette smoking and RA can allow a better understanding of the association.

Among the limitations of the present study, we have to consider the limited number of studies addressing the dose-response association between lifelong exposure to cigarette smoking and RA. Moreover, a meta-analysis is influenced by the quality of the summarized studies. The quality scale used in this manuscript indicates a moderate quality for all the studies. However, this quality scale does not take into account the differences between case-control and prospective cohort design, such as different biases (for example, case-control studies may be affected by recall bias, while prospective cohort are not). Moreover, the pooled estimate from this meta-analysis could have been affected by a potential residual confounding from each study. In particular, the numbers of confounders taken

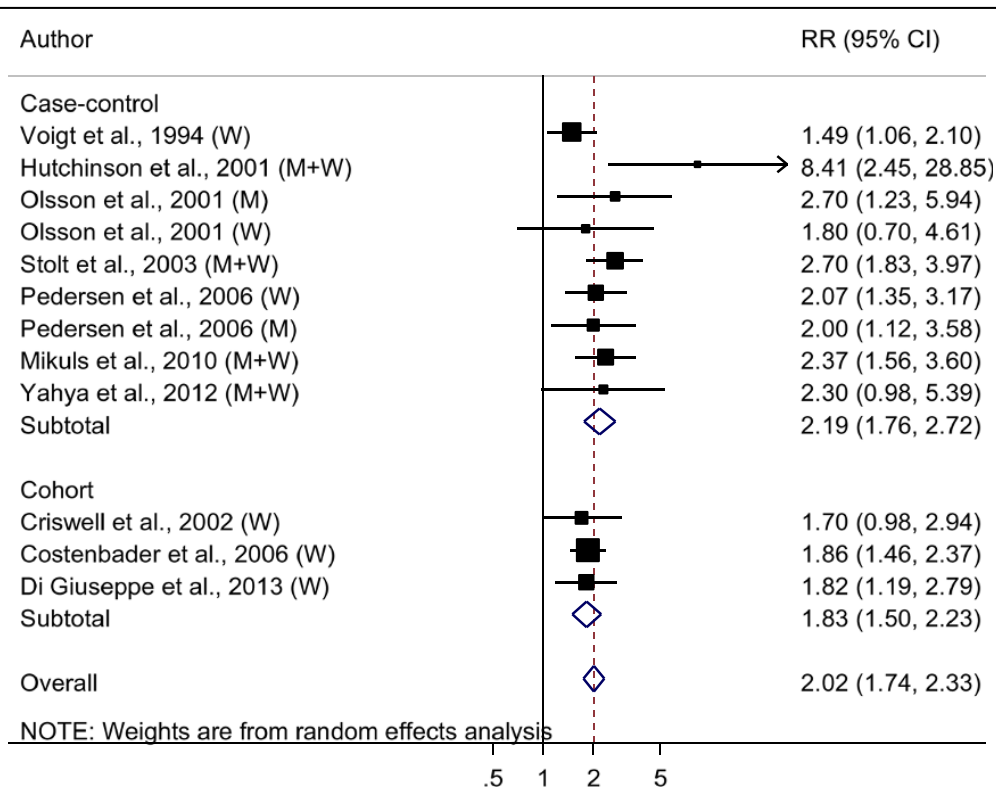

Figure 3 Forest plot of relative risk estimates for rheumatoid arthritis risk associated with pack-years of cigarette smoking (highest vs. lowest category). Cl indicates confidence intervals; RR indicates relative risk. The size of each square is proportional to the study's weight (inverse variance). *Test for heterogeneity: cohort studies, $P=0.96, I^{2}=0.0 \%$; case-control studies, $P=0.19, I^{2}=28.7 \%$, overall studies, $P=0.32, I^{2}=12.7 \%$. 
into account by the case-control studies included in this meta-analysis were in general limited. This could explain the difference between the pooled OR from case-control studies and the pooled RR from prospective cohort studies. Moreover, this difference could also be explained by the different study populations: prospective cohort studies analyzed only women while all case-control studies except one [16] included both men and women.

The biological effect of smoking in the development of rheumatoid arthritis is still unclear. However, it is known that certain cigarette smoke components, such as nicotine, hydrocarbons and carbon monoxide, may enhance immune reactions, and it has been found that in certain inbred strains of rodents these components cause arthritis without contributions from other agents [25-27]. Moreover, it has been hypothesized that smoking interacts with $H L A-D R S E$ genes in triggering and persuading immunity against citrullinated proteins, and that this immunity is specific for RA $[6,28]$. The observed non-linear shape of the dose-response association in this meta-analysis is compatible with this triggering mechanism. RF-positive RA is more likely to be associated with the HLA-DR4 shared epitope [29] than RF-negative RA. This can explain the difference in risk between RF-positive and RF-negative RA cases observed in the meta-analysis.

\section{Conclusion}

Our study showed some evidence of a non-linear doseresponse relationship between lifelong smoking and risk of RA. The risk increased at a relatively low level of lifelong exposure to smoking ( $\leq 10$ pack/years) and stabilized to approximately a double risk for a smoking exposure higher than 20 pack-years.

\section{Abbreviations}

ACPA: anticitrullinated protein antibody; AIC: Akaike Information Criterion; Cl: Confidence interval; NOQAS: Newcastle-Ottawa Quality Assessment Scale; OR: Odds ratio; RA: Rheumatoid arthritis; RF: Rheumatoid factor; RR: Relative risk.

\section{Competing interest}

The authors declare that they have no competing interests.

\section{Authors' contributions}

$\mathrm{DDG}, \mathrm{AD}, \mathrm{NO}$ and $\mathrm{AW}$ participated in the study design and in writing the manuscript. DDG, AD and NO participated in the data collection. DDG analyzed the data and wrote the manuscript under the supervision of AW. $\mathrm{DDG}, \mathrm{AD}, \mathrm{NO}$ and $\mathrm{AW}$ interpreted the data and critically reviewed the paper. All authors read and approved the final manuscript.

\section{Acknowledgement}

This work was supported by research grants from the Swedish Research Council/Committee for Medicine, from the Swedish Research Council/ Committee for Research Infrastructure for maintenance of the Swedish Mammography Cohort. Ms Di Giuseppe was supported by the Karolinska Institutet's Award for PhD students.

Received: 11 November 2013 Accepted: 10 February 2014 Published: 5 March 2014

\section{References}

1. Sugiyama D, Nishimura K, Tamaki K, Tsuji G, Nakazawa T, Morinobu A, Kumagai S: Impact of smoking as a risk factor for developing rheumatoid arthritis: a meta-analysis of observational studies. Ann Rheum Dis 2010, 69:70-81.

2. Stolt P, Bengtsson C, Nordmark B, Lindblad S, Lundberg I, Klareskog L, Alfredsson L, EIRA Study Group: Quantification of the influence of cigarette smoking on rheumatoid arthritis: results from a population based case-control study, using incident cases. Ann Rheum Dis 2003, 62:835-841.

3. Karlson EW, Lee IM, Cook NR, Manson JE, Buring JE, Hennekens $\mathrm{CH}$ : A retrospective cohort study of cigarette smoking and risk of rheumatoid arthritis in female health professionals. Arthritis Rheum 1999, 42:910-917.

4. Costenbader KH, Feskanich D, Mandl LA, Karlson EW: Smoking intensity, duration, and cessation, and the risk of rheumatoid arthritis in women. Am J Med 2006, 119:503. e501-503.e509.

5. Di Giuseppe D, Orsini N, Alfredsson L, Askling J, Wolk A: Cigarette smoking and smoking cessation in relation to risk of rheumatoid arthritis in women. Arthritis Res Ther 2013, 15:R56.

6. Klareskog L, Padyukov L, Alfredsson L: Smoking as a trigger for inflammatory rheumatic diseases. Curr Opin Rheumatol 2007, 19:49-54.

7. Karlson EW, Chang SC, Cui J, Chibnik LB, Fraser PA, De Vivo I, Costenbader $\mathrm{KH}$ : Gene-environment interaction between HLA-DRB1 shared epitope and heavy cigarette smoking in predicting incident rheumatoid arthritis. Ann Rheum Dis 2010, 69:54-60.

8. Källberg H, Ding B, Padyukov L, Bengtsson C, Rönnelid J, Klareskog L, Alfredsson L, EIRA Study Group: Smoking is a major preventable risk factor for rheumatoid arthritis: estimations of risks after various exposures to cigarette smoke. Ann Rheum Dis 2011, 70:508-511.

9. Wells G, Shea B, O'Connell D, Welch V, Losos M, Tugwell P: The Newcastle-Ottawa Scale (NOS) for Assessing The Quality Of Nonrandomised Studies in META-ANALYSES [article online]. Ottawa Hospital Research Institute, Ottawa, Ontario, Canada: Department of Epidemiology and Community Medicine, University of Ottawa. [http://www.ohri.ca/ programs/clinical_epidemiology/oxford.asp]

10. Liberati A, Altman DG, Tetzlaff J, Mulrow C, Gotzsche PC, loannidis JP, Clarke M, Devereaux PJ, Kleijnen J, Moher D: The PRISMA statement for reporting systematic reviews and meta-analyses of studies that evaluate healthcare interventions: explanation and elaboration. BMJ 2009, 339:b2700.

11. Greenland S, Longnecker MP: Methods for trend estimation from summarized dose-response data, with applications to meta-analysis. Am J Epidemiol 1992, 135:1301-1309.

12. Orsini N, Bellocco R, Greenland S: Generalized least squares for trend estimation of summarized dose-response data. Stata J 2006, 6:40-57.

13. Navarro-Compan V, Melguizo-Madrid E, Hernandez-Cruz B, Santos-Rey K, Leyva-Prado C, Gonzalez-Martin C, Navarro-Sarabia F, Gonzalez-Rodriguez C: Interaction between oxidative stress and smoking is associated with an increased risk of rheumatoid arthritis: a case-control study. Rheumatology (Oxford) 2012, 52:487-493.

14. Mikuls TR, Sayles H, Yu F, Levan T, Gould KA, Thiele GM, Conn D, Jonas BL, Callahan LF, Smith E, Brasington R, Moreland LW, Reynolds RJ, Bridges SL Jr: Associations of cigarette smoking with rheumatoid arthritis in African Americans. Arthritis Rheum 2010, 62:3560-3568.

15. Hamling J, Lee $P$, Weitkunat $R$, Ambuhl M: Facilitating meta-analyses by deriving relative effect and precision estimates for alternative comparisons from a set of estimates presented by exposure level or disease category. Stat Med 2008, 27:954-970.

16. Voigt LF, Koepsell TD, Nelson JL, Dugowson CE, Daling JR: Smoking, obesity, alcohol consumption, and the risk of rheumatoid arthritis. Epidemiology 1994, 5:525-532.

17. DerSimonian R, Laird N: Meta-analysis in clinical trials. Control Clin Trials 1986, 7:177-188.

18. Higgins JP, Thompson SG: Quantifying heterogeneity in a meta-analysis. Stat Med 2002, 21:1539-1558

19. Sterne JA, Egger M, Smith GD: Systematic reviews in health care: investigating and dealing with publication and other biases in meta-analysis. BMJ 2001, 323:101-105.

20. Criswell LA, Merlino LA, Cerhan JR, Mikuls TR, Mudano AS, Burma M, Folsom $A R$, Saag KG: Cigarette smoking and the risk of rheumatoid arthritis among postmenopausal women: results from the lowa Women's Health Study. Am J Med 2002, 112:465-471. 
21. Olsson Reckner A, Skogh T, Wingren G: Comorbidity and lifestyle, reproductive factors, and environmental exposures associated with rheumatoid arthritis. Ann Rheum Dis 2001, 60:934-939.

22. Pedersen $M$, Jacobsen $S$, Klarlund M, Pedersen BV, Wiik A, Wohlfahrt J, Frisch M: Environmental risk factors differ between rheumatoid arthritis with and without auto-antibodies against cyclic citrullinated peptides. Arthritis Res Ther 2006, 8:R133.

23. Yahya A, Bengtsson C, Lai TC, Larsson PT, Mustafa AN, Abdullah NA, Muhamad N, Hussein H, Klareskog L, Alfredsson L, Murad S: Smoking is associated with an increased risk of developing ACPA-positive but not ACPA-negative rheumatoid arthritis in Asian populations: evidence from the Malaysian MyEIRA case-control study. Mod Rheumatol 2012 22:524-531.

24. Hutchinson D, Shepstone L, Moots R, Lear JT, Lynch MP: Heavy cigarette smoking is strongly associated with rheumatoid arthritis (RA), particularly in patients without a family history of RA. Ann Rheum Dis 2001, 60:223-227.

25. Stämpfli MR, Anderson GP: How cigarette smoke skews immune responses to promote infection, lung disease and cancer. Nat Rev Immunol 2009, 9:377-384.

26. Domagala-Kulawik J: Effects of cigarette smoke on the lung and systemic immunity. J Physiol Pharamacol 2008, 59:19-34.

27. Holmdahl R, Lorentzen JC, Lu S, Olofsson P, Wester L, Holmberg J, Pettersson U: Arthritis induced in rats with nonimmunogenic adjuvants as models for rheumatoid arthritis. Immunol Rev 2001, 184:184-202.

28. Klareskog L, Stolt P, Lundberg K, Källberg H, Bengtsson C, Grunewald J, Rönnelid J, Harris HE, Ulfgren AK, Rantapää-Dahlqvist S, Eklund A, Padyukov $L$, Alfredsson L: A new model for an etiology of rheumatoid arthritis: smoking may trigger HLA-DR (shared epitope)-restricted immune reactions to autoantigens modified by citrullination. Arthritis Rheum 2006, 54:38-46.

29. Scott DL: Prognostic factors in early rheumatoid arthritis. Rheumatology (Oxford) 2000, 39:24-29.

\section{doi:10.1186/ar4498}

Cite this article as: Di Giuseppe et al:: Cigarette smoking and risk of rheumatoid arthritis: a dose-response meta-analysis. Arthritis Research \& Therapy 2014 16:R61.

\section{Submit your next manuscript to BioMed Central and take full advantage of:}

- Convenient online submission

- Thorough peer review

- No space constraints or color figure charges

- Immediate publication on acceptance

- Inclusion in PubMed, CAS, Scopus and Google Scholar

- Research which is freely available for redistribution 